\title{
Características cefalométricas de pacientes porta- dores de más oclusões Classe I e Classe II de Angle
}

Rogério Lacerda dos Santos* , Antônio Carlos de Oliveira Ruellas**

\section{Resumo}

Objetivos: o presente estudo comparou algumas medidas cefalométricas relacionadas às características faciais em pacientes com má oclusão Classe I, Classe II $1^{\text {a }}$ divisão e Classe II $2^{a}$ divisão. Metodologia: foram selecionadas 130 telerradiografias de pacientes leucodermas em fase inicial de tratamento ortodôntico, com idades entre 10 e 16 anos (média de 12,6 anos); e divididos em 3 grupos. As medidas cefalométricas utilizadas neste estudo foram: ANB, I-SN, IMPA, AML, Ls-ı̣, Li-ī e EI. A análise de variância e o teste de Tukey foram realizados nas medidas ANB, IMPA, AML, I-SN e Li-ī. Para as demais variáveis (EI e Ls-ı̣) foi utilizado o teste de Kruskal Wallis e Dunn. Resultados: os resultados mostraram que as medidas Ls-1 e EI tiveram diferença estatisticamente significativa entre os grupos I e II- 1 e entre os grupos II-1 e II-2 ( $p<0,05)$. As medidas ANB e IMPA tiveram diferença estatisticamente significativa entre os grupos I e II-1 e entre os grupos I e II-2 ( $<<0,05)$. A medida I-SN teve diferença estatisticamente significativa entre os 3 grupos $(p<0,05)$. Conclusões: pode-se concluir que a medida I-SN mostrou ser uma medida capaz de diferenciar os 3 tipos de más oclusões e a medida IMPA demonstrou que o comportamento axial dos incisivos inferiores em sua base óssea é bastante variável. A má oclusão Classe II $1^{\text {a }}$ divisão apresenta características faciais que a diferenciam da Classe II $2^{a}$ divisão e Classe I, quanto às medidas AML, Ls-ı̣ e EI. As más oclusões Classe II $1^{\text {a }}$ divisão, Classe II $2^{\text {a }}$ divisão e Classe I não apresentaram características faciais diferentes para a medida Li-̄̄.

Palavras-chave: Má oclusão. Cefalometria. Classificação de Angle.

\section{INTRODUÇÃO}

$\mathrm{Na}$ civilização egípcia, aproximadamente 5.000 anos atrás, já despontavam interesses pela estética e harmonia facial, estampadas nas artes da época. As faces idealizadas no "Velho Reinado" apresentavam-se arredondadas, a fronte inclinada e pouco saliente, o nariz bem contornado, os lábios espessos e o queixo com suave proeminência. Cerca de mil anos após, a famosa rainha
Nefertiti simbolizou um perfil facial moderno para a época, com mandíbula bem desenvolvida, como descrito por Peck e Peck ${ }^{23}$.

A harmonia tegumentar está intimamente relacionada com a posição do incisivo inferior ${ }^{30}$. A posição dos incisivos superiores está diretamente relacionada com a posição dos incisivos inferiores, que também são responsáveis pelo suporte labial, sendo o equilíbrio facial afetado

\footnotetext{
Especialista em Ortodontia pela Universidade Federal de Alfenas-UNIFAL. Mestrando em Ortodontia pela Universidade Federal do Rio de Janeiro-UFRJ.

** Mestre e doutor em Ortodontia pela Universidade Federal do Rio de Janeiro-UFRJ. Professor convidado do Curso de Especialização em Ortodontia da Universidade Federal de Alfenas-UNIFAL. Professor assistente do departamento de Odontopediatria e Ortodontia da Universidade Federal do Rio de Janeiro-UFRJ.
} 
diretamente por marcante protrusão e/ou apinhamento dos dentes ${ }^{18}$.

A noção de "perfil harmonioso" difere de pessoa para pessoa e de uma raça ou grupo étnico para outro. Em algum grau, esse conceito também muda ao longo do tempo, dependendo da experiência de indivíduos ou grupos. O perfil harmonioso, então, pode ser considerado uma variante, dependendo de fatores étnicos ou raciais e fatores temporais dos indivíduos, não podendo ser analisado exclusivamente por valores médios ou números ${ }^{6}$. Nem todas as partes de tecido mole seguem o perfil ósseo, resultado de um tecido mole fino, volumoso, flácido, rígido ou a combinação desses, sobre o contorno ósseo.

Nanda et al. ${ }^{21}$ verificaram maior crescimento na área do nariz e lábios, enquanto no mento o crescimento foi mínimo. $\mathrm{O}$ mento masculino não é tão proeminente quanto o feminino, mas isso não é devido a um maior mento nas mulheres e sim devido aos lábios não serem tão espessos e o sulco labial mais proeminente ${ }^{27}$. Os lábios crescem em comprimento e espessura com o avanço da idade e os aumentos diferem em função da idade e gênero. A espessura do lábio inferior aumenta, com a idade, bem mais nos homens do que nas mulheres ${ }^{14}$, sendo que o crescimento no comprimento do lábio superior completa-se na idade de $7 \operatorname{anos}^{21}$. O crescimento anteroposterior e projeção anterior do nariz continuam em ambos os gêneros após o fim do crescimento esqueletal e influencia grandemente na convexidade ou concavidade facial. Para as mulheres, grande parte do desenvolvimento do tecido mole é concluída aos 12 anos e nos homens continua até os 17 anos $^{10}$.

Segundo Herdy et al. ${ }^{11}$, a avaliação do perfil facial é de grande importância no tratamento ortodôntico, pois as alterações que ocorrem na face, observadas em norma lateral, podem influenciar na estética final. Bishara et $\mathrm{al} .^{3}$ demonstraram tendências essencialmente similares para o crescimento e desenvolvimento craniofacial em adolescentes com más oclusões Classe I e Classe II $1^{\mathrm{a}}$ divisão, exceto a protrusão de lábio superior e a convexidade de tecido mole com tendência à retrusão mandibular, que foram maiores para a Classe II $1^{\text {a }}$ divisão.

A variabilidade é uma constante na Biologia e, na face, obviamente, essa variação depende de fatores como idade, gênero, diferenças étnicas, raciais e fatores temporais, que juntos expressam o contorno facial em cada época. Diferenças expressivas quanto à posição anteroposterior dos lábios, principalmente na porção de tecido labial, nos últimos anos, manifestaram lábios mais salientes em contraste com os perfis do início do século $\mathrm{XX}$, que ostentavam lábios delgados e menos volumosos. Por décadas, busca-se comparar, relacionar e definir padrões e medidas confiáveis para a avaliação da estética facial, com o intuito de avaliar e definir confiabilidade na avaliação desses perfis. O presente estudo se propôs a comparar algumas medidas relacionadas ao tegumento anteroinferior da face de pacientes portadores de má oclusão Classe I, Classe II $1^{\text {a }}$ divisão e Classe II $2^{\text {a }}$ divisão, entre si e com as medidas padrão.

\section{MATERIAL E MÉTODOS}

Previamente, este trabalho foi enviado ao Comitê de Ética em Pesquisa da Escola de Farmácia e Odontologia de Alfenas, sendo aprovada a sua execução. Para o estudo, foram selecionadas 130 telerradiografias de pacientes leucodermas em fase inicial de tratamento ortodôntico, obtidas pela técnica de Broadbent ${ }^{5}$, com idade entre 10 e 16 anos (média de 12,6 anos), pertencentes à clínica do Curso de Especialização em Ortodontia da Escola de Farmácia e Odontologia de Alfenas/MG.

Os integrantes da amostra foram selecionados de maneira aleatória quanto ao gênero e nenhum deles havia sido submetido a tratamento ortodôntico de qualquer espécie e não poderiam apresentar mordidas cruzadas, mordida aberta e nem indicação para tratamento ortocirúrgico. A amostra foi dividida em três grupos. $\mathrm{O}$ primeiro, denominado grupo "I", composto de 50 indivíduos com má 
oclusão de Classe I, sendo 26 do gênero masculino e 24 do gênero feminino. $O$ segundo, denominado grupo "II-1", constituído de 50 indivíduos com má oclusão de Classe II $1^{a}$ divisão, sendo 25 do gênero masculino e 25 do gênero feminino e o terceiro denominado grupo "II-2", constituído de 30 indivíduos com má oclusão de Classe II $2^{\mathrm{a}}$ divisão, sendo 14 do gênero masculino e 16 do gênero feminino. As más oclusões foram classificadas pelo exame de modelos em gesso (relação molar, segundo Angle ${ }^{1}$ ) e medidas angulares cefalométricas (ANB, I.SN), sendo que todas as más oclusões Classe I de Angle eram Classe I esquelética (ANB entre $0^{\circ}$ e $4^{\circ}$ ) e todas as más oclusões Classe II $\left(1^{\mathrm{a}}\right.$ e $2^{\mathrm{a}}$ divisão) eram Classe II esquelética (ANB maior ou igual a $5^{\circ}$ ).

O método escolhido foi o de comparação de medidas cefalométricas. Todas as radiografias foram obtidas segundo as normas de padronização do $1^{\circ}$ workshop de cefalometria ${ }^{26}$. Todos os traçados foram realizados com objetivo de selecionar as estruturas anatômicas de interesse, e as medidas foram executadas por um único ortodontista, sendo conferidas duas vezes, em momentos diferentes.

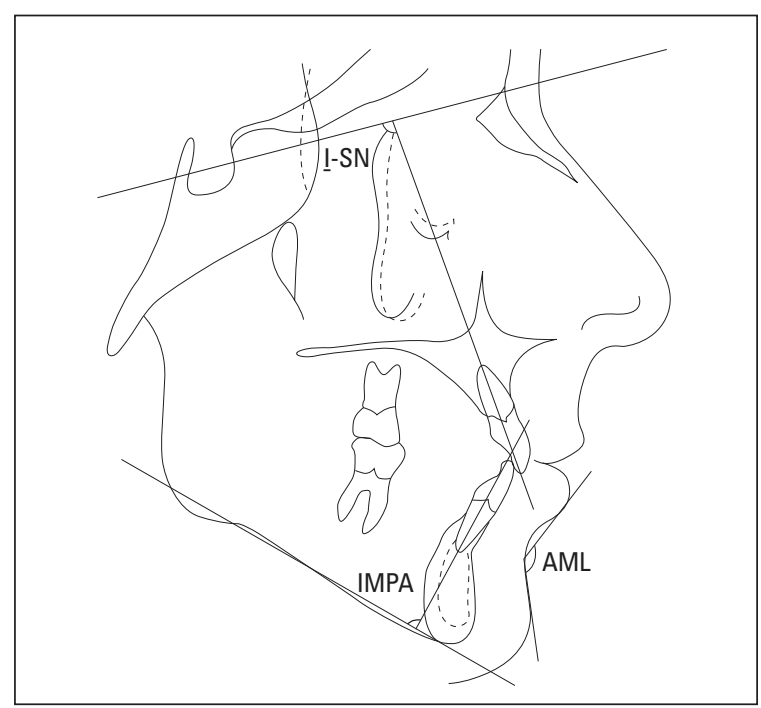

FIGURA 1 - Representação de medidas angulares do posicionamento dentário e do ângulo mentolabial.

\section{Medidas angulares usadas}

- Ângulo ANB: formado pela diferença entre os ângulos SNA e SNB. O valor padrão ${ }^{28}$ para os indivíduos com más oclusões Classe I deve ser de $0^{\circ}$ a $4^{\circ}$ (Fig. 2).

- Ângulo mentolabial (AML): formado pela interseção de uma linha que passa do ponto vermelhão do lábio inferior (LV) até o ponto B' e uma linha do ponto B' ao ponto pogônio mole (Pog'), o qual, segundo Nguyen e Turley ${ }^{22}$, deve ser de $128,5^{\circ}$ com desvio clínico de $\pm 11^{\circ}$ (Fig. 1).

- Ângulo I-SN: formado pela interseção do longo eixo do incisivo superior e da linha SN. O valor considerado ideal para este ângulo é de $103^{\circ}$, segundo Steiner ${ }^{29}$ (Fig. 1).

- Ângulo IMPA: formado pela interseção do longo eixo do incisivo inferior e do plano mandibular. O valor normativo desse ângulo deve ser de $90^{\circ} \pm 5$, segundo Tweed $^{30}$ (Fig. 1).

\section{Medidas lineares utilizadas}

- Ls-I (espessura Ls): distância do ponto mais anterior da convexidade do lábio superior ao ponto mais anterior do incisivo central superior (Fig. 2).

- Li-ĩ (espessura Li): distância do ponto mais

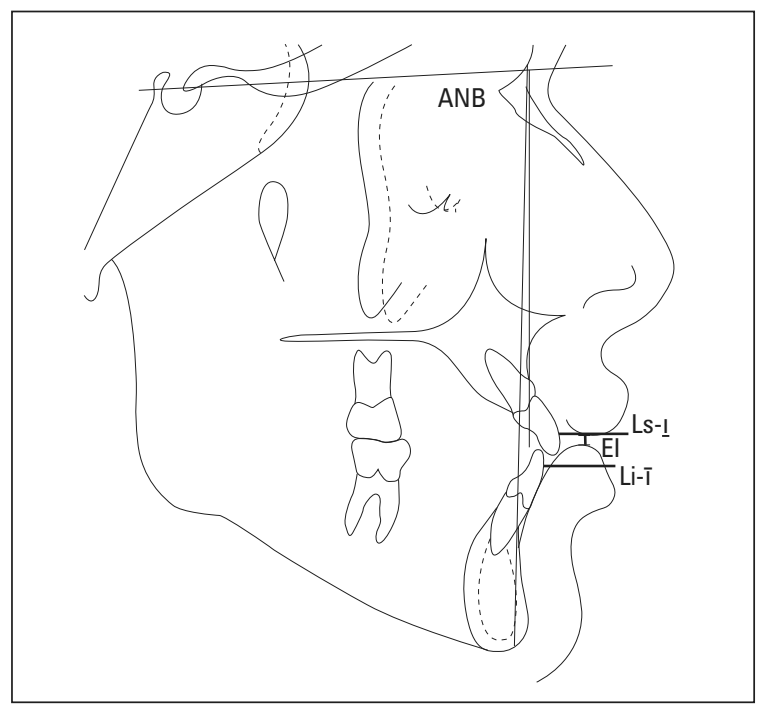

FIGURA 2 - Representação da medida angular da relação maxila/mandíbula e das medidas lineares do comportamento labial. 
anterior da convexidade do lábio inferior ao ponto mais anterior do incisivo central inferior (Fig. 2).

- EI: distância entre os pontos estômio do lábio superior e lábio inferior. $\mathrm{O}$ valor normativo desta medida é de 1 a $5 \mathrm{~mm}$, segundo Arnett e Bergman ${ }^{2}$ (Fig. 2).

\section{Análise estatística}

\section{Erro do método}

A fim de se avaliar o erro do método, aumentando-se a sua confiabilidade, foram selecionadas, aleatoriamente, 30 telerradiografias provenientes dos três grupos estudados. As radiografias foram traçadas novamente por um único operador, após um período de 1 mês do traçado inicial ${ }^{19}$.

Foi calculado o erro de acordo com a fórmula proposta por Dahlberg ${ }^{8}$ e defendida por Hous$\operatorname{ton}^{13}$. Foi realizado o teste $t$ pareado (para as variáveis com distribuição normal) e Wilcoxon pareado (para as variáveis EI e Ls-1 ), comparando-se os 2 momentos, com nível de significância de 5\%. Os valores dos desvios foram inferiores aos limites aceitáveis para avaliação do erro de método, que são de 1,5 graus para as medidas angulares e $1,0 \mathrm{~mm}$ para as medidas lineares, segundo as recomendações de Houston ${ }^{13}$.

\section{Análise dos dados}

Inicialmente, foi realizada uma análise exploratória dos dados usando o Proc Lab do programa estatístico SAS (SAS Institute Inc., Cary, NC, USA, Release 8.2, 2001). Para os dados que atenderam as pressuposições da análise paramétrica (ANB, IMPA, AML, Li-ī e I-SN), foram realizados a análise de variância e o teste de Tukey. Para as demais variáveis (Ls-ı̣ e EI), como não atendiam as pressuposições da análise paramétrica, foi utilizado o teste de Kruskal Wallis e Dunn. Para algumas variáveis, foi utilizada a mediana em vez da média, devido ao fato de algumas medidas terem se mostrado discrepantes e não indicadas para a realização da média. Porém, isso não lesa os objetivos desse estudo, uma vez que o teste aplicado para uma variável era o mesmo para os três tipos de más oclusões e essas comparadas entre si, buscando a semelhança entre elas. Em todas as análises foi considerado o nível de significância de $5 \%$.

\section{RESULTADOS E DISCUSSÃO}

A medida ANB apresentou diferença estatisticamente significativa entre os grupos I e II-1 e entre os grupos I e II-2 ( $<<0,05)$ (Gráf. 1), o que corrobora com achados de Riedel ${ }^{25}$. Ao ponderar o desvio-padrão (d.p.), os grupos II-1 e II-2 apresentaram 1,38 e 1,32, respectivamente, maiores do que o apresentado pelo grupo I $(1,01)$. Isso foi reflexo das maiores variações dos valores apresentadas pelas medidas das más oclusões Classe II, que têm um comportamento diferente no padrão de crescimento da oclusão normal e da Classe I de Angle, com ANB maior ${ }^{3}$, referente às variações no padrão esquelético, que podem estar relacionadas à inclinação da base do crânio e ao crescimento do complexo maxilomandibular facial no sentido anteroposterior e vertical ${ }^{9}$ e mascarar o valor do $\mathrm{ANB}^{6,12,21}$.

A medida I-SN apresentou diferença estatisticamente significativa entre os 3 grupos $(\mathrm{p}<0,05)$ (Gráf. 2), corroborando com os achados de Rie$\operatorname{del}^{25}$, e mostrou ser uma medida capaz de diferenciar essas más oclusões. Porém, ao se ponderar o desvio-padrão, observa-se que o mesmo apresentou valores expressivos para todas as más oclusões (6,02 grupo I; 6,39 grupo II-1; 5,18 grupo II-2). Isso sugere variações na inclinação da base craniana e inclinação axial do incisivo superior, que pode sofrer variações resultantes de fatores inerentes ao crescimento esquelético anteroposterior ${ }^{6,12,21}$, musculatura peribucal, língua e posicionamento dos dentes antagonistas ${ }^{24}$.

A medida IMPA apresentou diferença estatisticamente significativa entre os grupos I e II-1 e entre os grupos I e II-2 ( $p<0,05)$ (Gráf. 3). O desvio-padrão expressivo (5,39 grupo I; 7,35 grupo II-1; 8,45 grupo II-2), principalmente nas más 


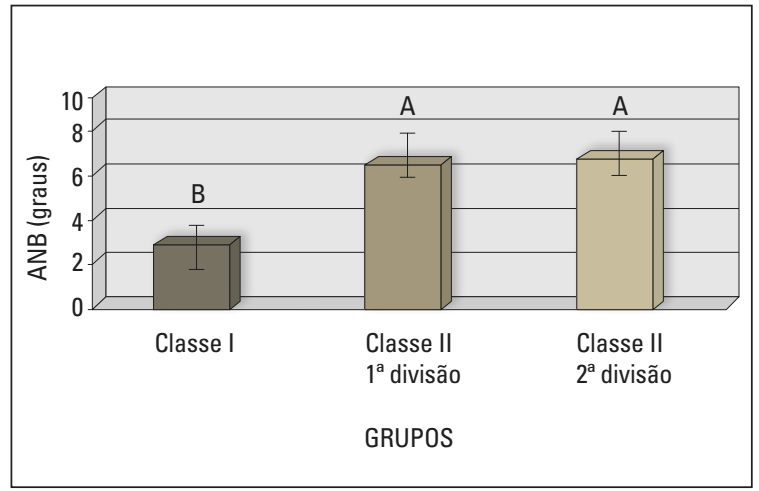

GRÁFICO 1 - Gráfico de médias da grandeza angular ANB. Letras iguais significam sem diferença estatisticamente significativa $(p<0,05)$.

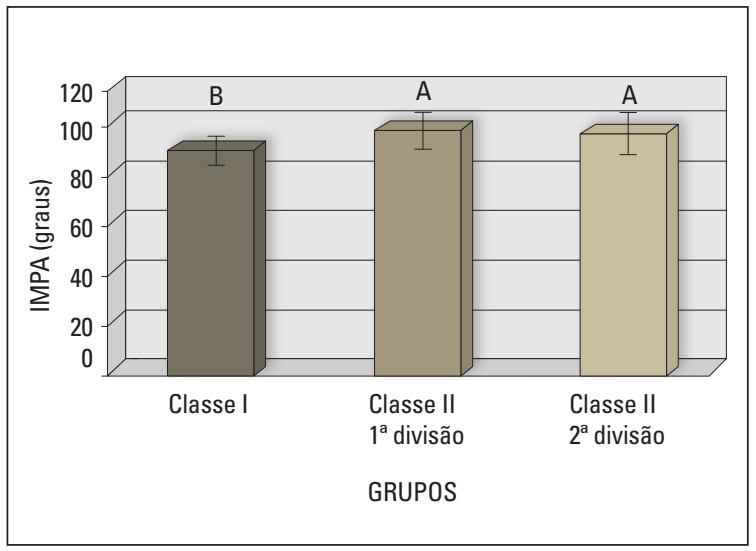

GRÁFICO 3 - Gráfico de médias da grandeza angular IMPA. Letras iguais significam sem diferença estatisticamente significativa $(p<0,05)$.

oclusões Classe II, demonstra que o comportamento axial dos incisivos inferiores em sua base óssea (IMPA) é bastante variável, semelhante aos achados de Tweed $^{30}$ para o grupo Classe I e superior ao encontrado por Tweed para as más oclusões Classe II. Depende, também, de outros fatores, como a musculatura peribucal, língua, overjet, overbite, presença de hábitos, do crescimento e as características próprias de cada indivíduo ${ }^{24}$. Vale ressaltar a similaridade encontrada para as medidas dos grupos II-1 e II-2, que apresentaram a mesma projeção de incisivos inferiores independentemente da má oclusão para a compensação da Classe II $^{17}$.

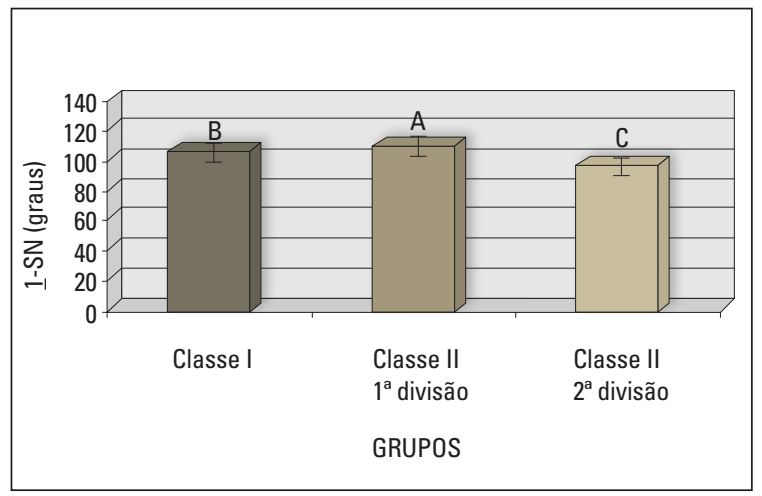

GRÁFICO 2 - Gráfico de médias da grandeza angular I-SN. Letras iguais significam sem diferença estatisticamente significativa $(p<0,05)$.

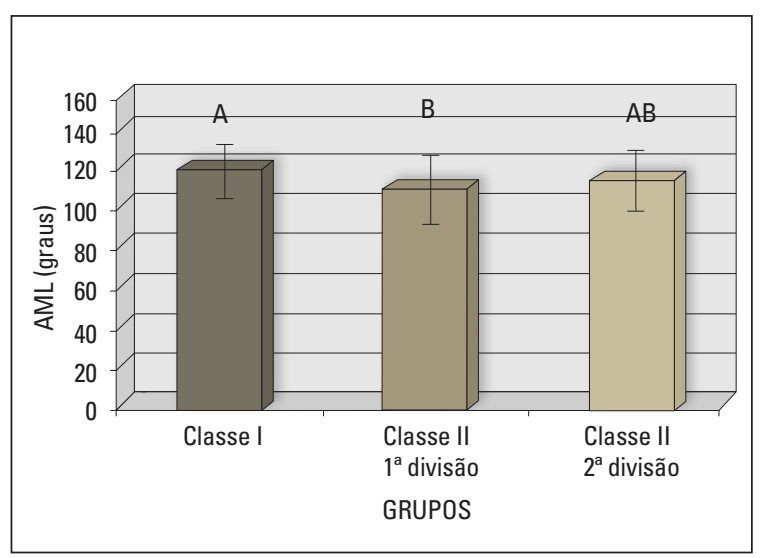

GRÁFICO 4 - Gráfico de médias da grandeza angular AML. Letras iguais significam sem diferença estatisticamente significativa $(p<0,05)$.

O ângulo AML apresentou diferença estatisticamente significativa apenas entre os grupos I e II-1 ( $\mathrm{p}<0,05)$ (Gráf. 4), semelhante aos achados de Nguyen e Turley ${ }^{22}$ para o grupo I e inferiores para o grupo II, com desvio-padrão expressivo para todos os grupos $(13,26$ grupo I; 16,80 grupo II-1; 15,44 grupo II-2) reflexo de variações para o posicionamento labial. Pôde-se constatar uma maior expressividade no grau de eversão do lábio inferior para o grupo II-1, devido a uma maior protrusão e projeção (I-SN) do incisivo superior para esse grupo. Apesar do posicionamento mais anterior do incisivo superior para o grupo II-2, 


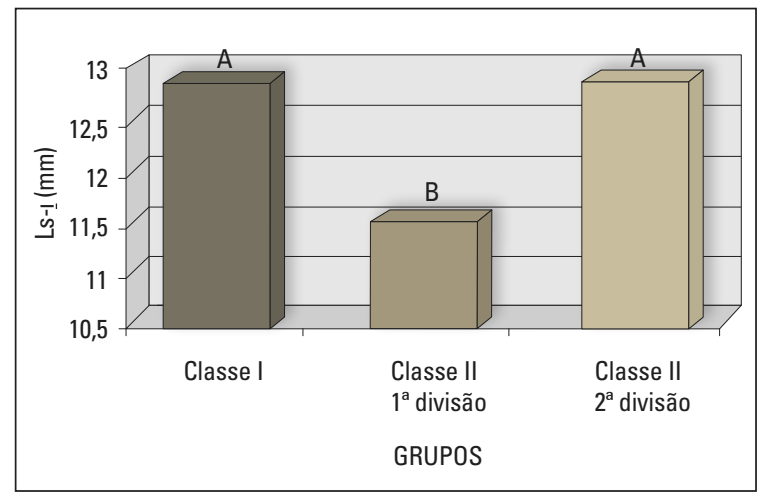

GRÁFICO 5 - Gráfico de medianas da grandeza linear Ls-I. Letras iguais significam sem diferença estatisticamente significativa $(p<0,05)$.

esse grupo não apresentou eversão significativa, apresentando valores similares ao grupo I, resultado da compensação entre a retroinclinação existente nos incisivos superiores (I-SN) e da projeção dos incisivos inferiores (IMPA) ${ }^{4}$.

A medida linear Ls- 1 apresentou diferença estatisticamente significativa entre os grupos I e II-1 e entre os grupos II-1 e II-2 ( $<<0,05)$ (Gráf. 5), semelhante aos valores encontrados por Massahud ${ }^{16}$. A espessura labial superior para o grupo II-1 foi menor que nos outros 2 grupos, pode-se admitir que existe tendência de correlação positiva entre a protrusão e projeção do incisivo superior com a espessura labial superior ${ }^{9,15,24}$, que apresentou-se maior para o grupo II-1 (I-SN).

A medida linear Li-ī não apresentou diferença estatisticamente significativa em nenhum dos 3 grupos ( $p>0,05$ ) (Gráf. 6), semelhante aos valores encontrados por Massahud ${ }^{16}$. $\mathrm{O}$ desvio-padrão apresentou-se com valores pouco expressivos e similares, o que faz com que a espessura do lábio inferior seja independente do tipo de má oclusão (Classe I ou Classe II) e/ou outros fatores, salvo fatores intrínsecos de cada indivíduo ${ }^{20}$, apesar de parecer irrelevante, sofrendo, dessa forma, apenas mudança no seu posicionamento espacial, mas não na espessura ${ }^{7}$.

A medida linear EI mostrou diferença estatis-

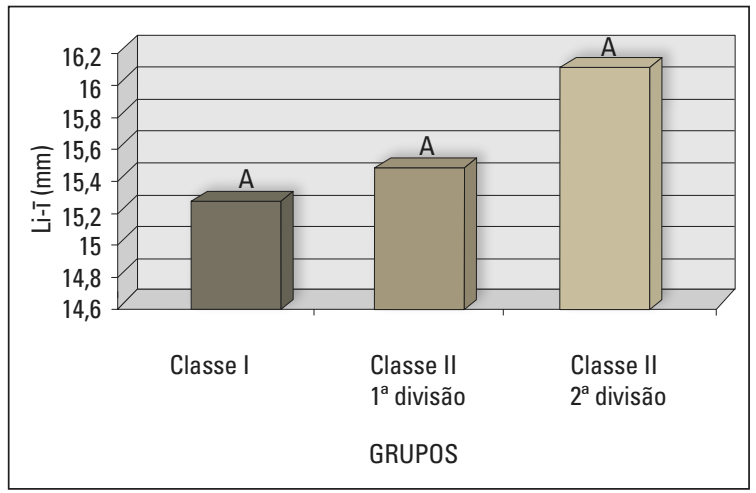

GRÁFICO 6 - Gráfico de médias da grandeza linear Li-T. Letras iguais significam sem diferença estatisticamente significativa $(p<0,05)$.

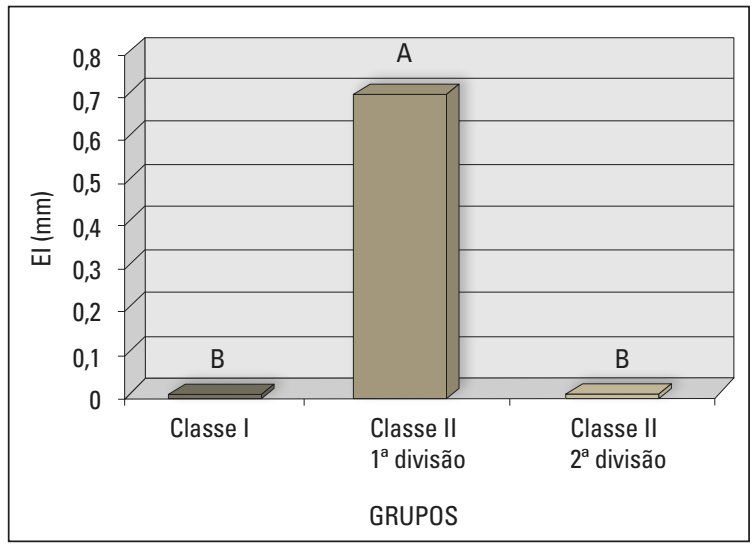

GRÁFICO 7 - Gráfico de medianas da grandeza linear El. Letras iguais significam sem diferença estatisticamente significativa $(p<0,05)$.

ticamente significativa entre os grupos I e II-1 e entre os grupos II-1 e II-2 ( $<<0,05)$ (Gráf. 7), semelhante aos achados de Arnett e Bergman ${ }^{2}$. O valor encontrado para o grupo II-2 foi similar ao do grupo I, reflexo da compensação entre retroinclinação do incisivo superior e projeção do incisivo inferior, que favoreceu o equilíbrio labial ${ }^{24}$. O grupo II-1 apresentou-se dentro da medida padrão, porém foi a medida que apresentou as maiores variações, demonstrando o comportamento dessa medida, que pode estar associado a fatores como o comprimento labial, posição dos incisivos, crescimento alveolar e presença de hábitos ${ }^{24}$. 


\section{CONCLUSÃO}

- A medida ANB apresentou as maiores variações de valores para as medidas das más oclusões Classe II, havendo uma predominância de deficiência de crescimento mandibular.

- A medida I-SN mostrou ser uma medida capaz de diferenciar os 3 tipos de más oclusões, sendo maior no grupo II-1 e menor no grupo II-2.

- A medida IMPA demonstrou que o comportamento axial dos incisivos inferiores em sua base óssea é bastante variável.
- A má oclusão Classe II $1^{a}$ divisão apresenta características faciais que a diferenciam da Classe II $2^{a}$ divisão e Classe I, quanto às medidas AML, Ls-l e EI.

- As más oclusões Classe II $1^{\text {a }}$ divisão, Classe II $2^{\text {a }}$ divisão e Classe I não apresentaram características faciais diferentes para a medida Li-ī.

\title{
Cephalometric characteristics of patients with Angle Class I and Class II malocclusions
}

\begin{abstract}
Aim: The present study compared some cephalometric measurements related to facial characteristics in patients having Class I, Class II division 1, and Class II division 2 malocclusions. Methods: One hundred and thirty teleradiographs of Caucasian patients aged 10-16 years (mean age of 12.6 years) under initial orthodontic treatment were selected for study and divided into 3 groups. The cephalometric measurements used in the present study were the following: ANB, I-SN, IMPA, AML, Ls-1ㅡ, Li-T, and El. Variance analysis and Tukey's test were carried out for ANB, IMPA, AML, L-SN, and Li-ī measurements, whereas Kruskal-Wallis and Dunn's tests were used for EI and Ls-1. Results: Statistically significant differences were found for EI and Ls-1 measurements when Group II-1 was compared to Group I and Group II-2 ( $<<0.05)$. ANB and IMPA measurements also had statistically significant differences when Group I was compared to Group II-1 and Group II-2 ( $p<0.05)$. The measurement I-SN had statistically significant differences between the 3 groups $(p<0.05)$. Conclusions: One can conclude that the measurement I-SN was found to be capable of differentiating the 3 types of malocclusions, whereas measurement IMPA showed that lower incisors have a variable axial behavior regarding their osseous bases. Based on the AML, EI and Ls-ımeasurements, Class II division 1 malocclusion was found to have facial characteristics which differentiate it from Class II division 2 and Class I malocclusions. Class II division 1, Class II division 2, and Class I malocclusions did not show different facial characteristics regarding the measurement Li-T.
\end{abstract}

Keywords: Malocclusion. Cephalometry. Angle's classification.

\section{REFERÊNCIAS}

1. ANGLE, E. H. Classification of malocclusion. Dental Cosmos, Philadelphia, v. 41, p. 255-264, 1899.

2. $\quad$ ARNETT, G. W.; BERGMAN, R. T. Facial keys to orthodontic diagnosis and treatment planning - Part I. Am. J. Orthod. Dentofacial Orthop., St. Louis, v. 103, no. 4, p. 299-312, Apr. 1993.

3. BISHARA, S. E. et al. Changes in dentofacial structures in untreated Class II division 1 and normal subjects: a longitudinal study. Angle Orthod., Appleton, v. 67, no. 1, p. 55-66, 1997.
4. BRANDÃO, A. M. B.; VIGORITO, J. W.; CAPELOZZA FILHO, L. Avaliação das características do perfil tegumentar em pacientes com má oclusão Classe II, $1^{a}$ divisão por meio da análise facial numérica. Ortodontia, São Paulo, v. 34, n. 2, p. 59-85, maio/ago. 2001.

5. BROADBENT, B. H. A new $\mathrm{X}$-ray technique and its application to Orthodontia. Angle Orthod., Appleton, v. 1, no. 2, p. 45-66, Apr. 1931.

6. BURSTONE, C. J. The integumental profile. Am. J. Orthod., St. Louis, v. 44, no. 1, p. 1-25, Jan. 1958. 
7. CZARNECKI, S. T.; NANDA, R. S.; CURRIER, G. F. Perceptions of a balanced facial profile. Am. J. Orthod. Dentofacial Orthop., St. Louis, v. 104, no. 2, p. 180-187, Aug. 1993.

8. DAHLBERG, G. Statistical methods for medical and biological students. New York: Interscience, 1940.

9. DAINESI, E. A. et al. Estudo das alterações do perfil tegumentar em jovens braquifaciais. Disponível em: <http://www.apcd.org.br/biblioteca/revista/2000/set_ out/409.asp>. Acesso em: 22 ago. 2004

10. GENECOV, J. S. et al. Developing of soft tissue facial profile and nose. Angle Orthod., Appleton, v. 60, no. 3, p. 191-198, July/Sept. 1990.

11. HERDY, J. L. A.; NOUER, P. R. A.; JUNQUEIRA, J. L. C.; CARNEIRO, E. H. Morfologia e alterações do perfil facial durante o crescimento. Ortodontia, São Paulo, v. 35, n. 2, p. 109-119, jun. 2002

12. HOLDAWAY, R. A.; MERRIFIELD, L. L. A soft-tissue analysis and its use in orthodontic treatment planning. Part I. Am J. Orthod., St. Louis, v. 84, no. 1, p. 1-28, July 1983.

13. HOUSTON, W. J. B. The analysis of errors in orthodontic measurements. Am. J. Orthod. Dentofacial Orthop. St. Louis, v. 83, no. 5, p. 382-390, May 1983.

14. MAMANDRAS, A. H. Linear changes of the maxillary and mandibular lips. Am. J. Orthod. Dentofacial Orthop., St. Louis, v. 94, no. 5, p. 405-410, Nov. 1988.

15. MARIA, F. R. T.; ROSSATO, C. Avaliação do ângulo nasolabial e do lábio superior em jovens tratados ortodonticamente com extrações de quatro pré-molares. Rev. Dental Press Ortodon. Ortop. Facial, Maringá, v. 10, n. 3, p. 23-35, maio/jun. 2005.

16. MASSAHUD, N. V. Estudo cefalométrico comparativo das alterações no perfil mole facial pré e pós-tratamento ortodôntico com extrações de pré-molares. 2002. Trabalho de Conclusão de Curso (Especialização)-Faculdade de Odontologia, Escola de Farmácia e Odontologia de Alfenas, Alfenas, 2002

17. MERRIFIELD, L. L. Differential diagnosis. Semin. Orthod., Philadelphia, v. 2, no. 4, p. 241-253, Dec. 1996.

18. MERRIFIELD, L. L. The profile line as an aid in critically evaluating facial esthetic. Am. J. Orthod., St. Louis, v. 57, no. 11, p. 804-822, Nov. 1966.
19. MIDTGARD, J. BJORK, G. LINDER-ARONSON, S Reproducibility of cephalometric landmarks and errors of measurements of cephalometric cranial distances. Angle Orthod., Appleton, v. 44, no. 1, p. 56-61, Jan. 1974.

20. MOTA, A. F. J.; BOLOGNESE, A. M. Estudo cefalométrico dos efeitos da extração de segundos pré-molares inferiores em pacientes submetidos a tratamento ortodôntico. JBO: J. Bras. Ortod. Ortop. Facial, Curitiba, ano 5, n. 30, nov./dez. 2000.

21. NANDA, R. S. et al. Perceptions of a balanced facial profile. Am. J. Orthod. Dentofacial Orthop., St. Louis, v. 114, no. 2, p. 180-187, Aug. 1993.

22. NGUYEN, D. D.; TURLEY, P. K. Changes in the caucasian male facial profile as depicted in fashion magazines during the twentieth century. Am. J. Orthod. Dentofacial Orthop. St. Louis, v. 114, no. 2, p. 208-217, Aug. 1998.

23. PECK, H.; PECK, S. A. A concept of facial esthetics. Angle Orthod., Appleton, v. 40, no. 4, p. 284-218, Oct. 1970.

24. RICKETTS, R. M. Esthetics, environment and the law of lip relation. Am. J. Orthod., St. Louis, v. 54, no. 4, p. 272-289, Apr. 1968.

25. RIEDEL, R. A. The relation of maxillary structures to craniun in malocclusion and in normal occlusion. Angle Orthod., Appleton, v. 22, no. 3, p. 142-145, July 1952.

26. SALZMANN, J. A. First roentgenographic cephalometric workshop. Am. J. Orthod., St. Louis, v. 44, no. 12, p. 899-900, Dec. 1958.

27. SPRADLEY, F. L. et al. Anteroposterior soft-tissue contour of lower facial third in ideal young adult. Am. J. Orthod. Dentofacial Orthop., St. Louis, v. 79, no. 3, p. 316-325, Mar. 1981.

28. STEINER, C. C. Cephalometrics for you and me. Am. J. Orthod., St. Louis, v. 39, no. 10, p. 729-755, Oct. 1953.

29. STEINER, C. C. Cephalometric as a clinical tool. In: KRAUS, B. S.; RIEDEL, R. A. (Ed.). Vistas in Orthodontics. Philadelphia: Lea \& Febiger, 1962. p. 30-38.

30. TWEED, C. H. Indications for extraction of teeth in orthodontic procedure. Am. J. Orthod., St. Louis, v. 30, no. 2, p. 405-428, Feb. 1944.
Endereço para correspondência

Rogério Lacerda dos Santos

Pça. José Batista de Freitas, 78, sala 102 - Centro

CEP: 35.519-000 - Nova Serrana / MG

E-mail: lacerdaorto@hotmail.com - lacerdaorto@bol.com.br 